\title{
Correction to: Pseudovasculitis: an etiology not to miss
}

\author{
Scott A. Elman ${ }^{1}$ - Daniel R. Mazori ${ }^{1}$. Joseph F. Merola ${ }^{1,2}$
}

Published online: 1 February 2021

(C) International League of Associations for Rheumatology (ILAR) 2021

\section{Correction to: Clinical Rheumatology https://doi.org/10.1007/s10067-020-05548-9}

In the original published version of the above article, the legend of Fig. 1 was revised. The legend for Fig. $1 \mathrm{~b}$ mentioned splinter hemorrhages. However, there are no splinter hemorrhages in Fig. 1b, only in Fig. 1a. The original article has been corrected.

Publisher's note Springer Nature remains neutral with regard to jurisdictional claims in published maps and institutional affiliations.

The online version of the original article can be found at https://doi.org/ $10.1007 / \mathrm{s} 10067-020-05548-9$

Joseph F. Merola

jfmerola@bwh.harvard.edu

1 Department of Dermatology, Brigham and Women's Hospital, Harvard Medical School, 221 Longwood Ave, Boston, MA, USA

2 Division of Rheumatology, Department of Medicine, Brigham and Women's Hospital, Harvard Medical School, 221 Longwood Ave, Boston, MA, USA 